\title{
Tuning the regioselective functionalization of trifluoromethylated dienes via lanthanum-mediated single $C-F$ bond activation
}

\author{
Tarun Kumar, ${ }^{[a] b]}$ Yan Yang, ${ }^{[c]}$ Sirine Sghaier, ${ }^{[a]}$ Yassir Zaid, ${ }^{[a]}$ Xavier F. Le Goff, ${ }^{[d]}$ Elodie Rousset, ${ }^{[b]}$ \\ Fabien Massicot, ${ }^{[b]}$ Dominique Harakat, ${ }^{[b]}$ Agathe Martinez, ${ }^{[b]}$ Marc Taillefer, ${ }^{[a]}{ }^{[a}$ Laurent Maron, ${ }^{[c]}$ Jean- \\ Bernard Behr, ${ }^{[b]}$ Florian Jaroschik*[a]
}

\begin{abstract}
The development of new fluorine containing building blocks and their efficient synthetic access is currently a challenging research field. We herein present the highly regio and stereoselective addition of a large range of aldehydes onto trifluoromethylated benzofulvenes using a simple La/ $\mathrm{L}_{2} / \mathrm{DIBAL}$ Cl system via a selective C-F bond activation process. This versatile methodology provides homodienyl alcohols bearing a terminal $\mathbf{C F}_{2}$-alkene with potential further applications, as shown by the dehydration to the first benzofulvenes carrying a difluorovinyl group. In addition, for certain electron-poor aldehydes, unprecedented ipso substitution of the $\mathrm{CF}_{3}$ group in a diene has been observed, which according to DFT studies, is related to the presence of the large, Lewis acidic lanthanum metal.
\end{abstract}

The increasing demand of fluorinated materials in many technological areas as well as in the pharmaceutical and agrochemical domains requires the search for new F-containing building blocks and their efficient synthetic access. ${ }^{1}$ Selective C$\mathrm{F}$ bond activation in readily available polyfluorinated substrates is currently investigated as a powerful alternative to diverse fluorination procedures. ${ }^{2}$ Polyfluorinated arenes have been at the center of research for a long time,$^{3}$ however, recent years have seen the development of efficient and selective C-F bond cleavage in aromatic, aliphatic or vinylic $\mathrm{CF}_{3}$ groups as well. ${ }^{4}$ Among the latter, 2-trifluoromethyl-1-alkenes are versatile substrates which can readily provide a wide range of difluoroalkenes either through rather common $S_{N} 2$ ' reactions with a variety of nucleophiles or photochemically generated radicals, or via Lewis acid mediated/catalyzed $S_{N} 1$ ' processes (Scheme 1a). ${ }^{5}$ Very recently, ipso-substitution has also been achieved on vinylic $\mathrm{CF}_{3}$ substrates, offering an alternative for the

[a] Dr. T. Kumar, Ms. S. Sghaier, Dr. Y. Zaid, Dr. M. Taillefer, Dr. F. Jaroschik

ICGM, Université de Montpellier, CNRS, ENSCM

34090 Montpellier, France

E-mail: florian.jaroschik@enscm.fr

[b] Dr. T. Kumar, Dr. E. Rousset, Dr. F. Massicot, Dr. D. Harakat, Ms.

A. Martinez, Prof. J.-B. Behr,

Université de Reims Champagne Ardenne, CNRS, ICMR UMR

7312, 51097 Reims, France

[c] Ms. Y. Yang, Prof. L. Maron

LPCNO, Université de Toulouse, UPS, INSA, CNRS

135 avenue de Rangueil - 31077 Toulouse, France

[d] Dr. X. Le Goff

ICSM, Université de Montpellier, CEA, CNRS, ENSCM,

30207 Bagnols-sur-Cèze, France regioselective functionalization of such compounds (Scheme 1a). ${ }^{6}$ In the meanwhile, trifluoromethyl-1,3-dienes are much less investigated because of their limited synthetic access. ${ }^{7} \mathrm{~A}$ selective photochemical process has recently shown a promising radical addition of alkyl groups on such substrates providing new 1,1-difluorodienes (Scheme 1b). ${ }^{8}$ In 2017, we reported on the selective transformation of $\mathrm{CF}_{3}$-benzofulvenes into 1,1-indenyl species using a $\mathrm{Dy} / \mathrm{AlCl}_{3}$ system. In this preliminary work, initial metal-mediated $\mathrm{C}-\mathrm{F}$ activation afforded a conjugated $\varepsilon, \varepsilon$-difluoropentadienyl nucleophilic species with a high tendency to react regioselectively with a series of aldehydes, affording the quaternary, branched product (Scheme 1c).$^{9}$

a)

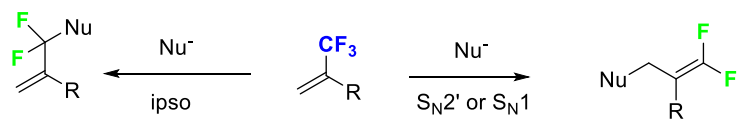

b)

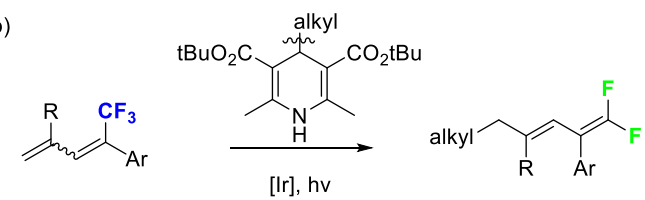

c)

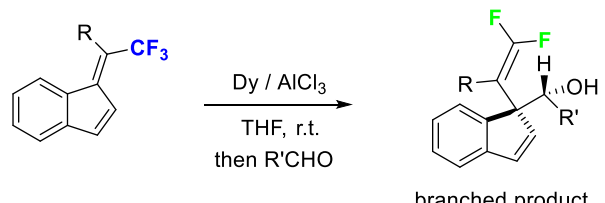

d) This work

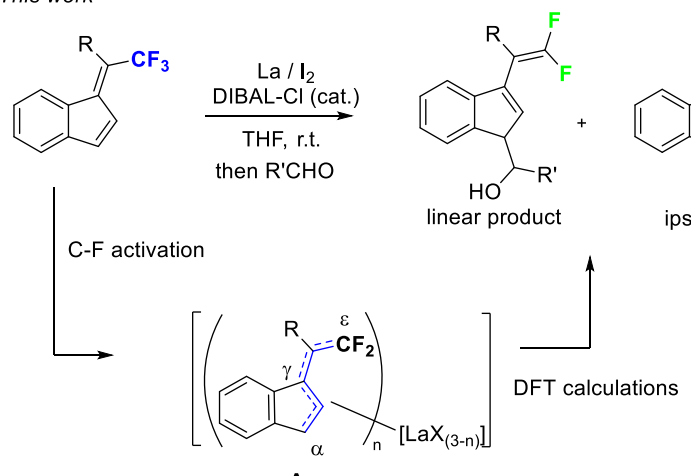

A

Scheme 1. Recent progress in selective single C-F bond activation in $\mathrm{CF}_{3}$ alkenes and dienes (past and present work) 
We herein present how further investigations on these substrates provided regio and diastereoselective access to the linear product, which can be readily transformed to a new family of benzofulvenes carrying a difluoroalkene moiety. Most intriguingly, in the course of these studies we also observed the first ipso-substitution of the $\mathrm{CF}_{3}$ group in a $\mathrm{CF}_{3}$-diene moiety (Scheme 1d). In addition, DFT calculations were carried out to rationalize the regioselectivity of this transformation in light of the structures of the putative organometallic intermediate $\mathbf{A}$ (Scheme 1d).

In our previous study on the addition of $\mathrm{CF}_{3}$-benzofulvene $1 \mathrm{a}$ onto $p$-bromobenzaldehyde $\mathbf{2 a}$ in the presence of lanthanoids, we have shown that the regiochemical outcome depends on the nature of the metal (Table 1, entries 1-2)..$^{9}$ Whereas specific $y$ addition could be observed with $\mathrm{Dy} / \mathrm{AlCl}_{3}$ affording the branched isomer 3aa in very high yield, a combination of $\mathrm{La}$ with $\mathrm{AlCl}_{3}$ provided a significant amount of the linear by-product 4aa via $\alpha-$ addition. However, under the tested conditions we were not able to switch the selectivity towards the sole linear isomer. By varying the electrophilic partner, we also found that steric factors could mediate the reaction outcome..$^{9,10}$ The bulky mesitaldehyde and $t$-butylaldehyde furnished mixtures of linear and branched products even when using the $\mathrm{Dy} / \mathrm{AlCl}_{3}$ system. Combining these two observations we set out to adjust the experimental conditions to secure specific alpha addition. As shown in Table 1, changing the amount, size and the electronic properties of the aluminum Lewis acid in combination with $\mathrm{La}$ metal provided a significant increase in the yield of the linear product (entries 2-6). Addition of only one equivalent of $\mathrm{AlCl}_{3}$ (entry 3 ) or the use of $\mathrm{EtAlCl}_{2}$ (entry 4) lowered the overall yield, however, a better diastereoselectivity (78 \% de) was observed for 4aa compared to the initial conditions ( $44 \%$ de, entry 2). Interestingly, compound 4aa became predominant in the presence of $\mathrm{Et}_{2} \mathrm{AICl}$ or ${ }^{1} \mathrm{Bu}_{2} \mathrm{AICl}$ and the diastereoselectivity improved significantly with the dialkylaluminium chlorides. The increased de values in entries 3-6 might be related to a shift in the equilibrium between the lanthanum and aluminium intermediates in the reaction process (see below and mechanistic studies in the SI, section III). Nevertheless, even with such bulky Lewis acids some branched product formed $(9 \%$ of 3 aa vs $74 \%$ of 4 aa with ${ }^{B} \mathrm{Bu}_{2} \mathrm{AlCl}$ ). In the literature, allyl lanthanide complexes are known to provide high selectivity towards the linear product in the reaction with carbonyl compounds. ${ }^{11}$ We therefore attempted to carry out this reaction in the absence of any aluminum source. Reaction of an excess of lanthanum metal with some iodine in THF provided in situ $\mathrm{Lal}_{3}(\mathrm{THF})_{\times}$which served as Lewis acid in this case. After stirring for one hour, the benzofulvene 1a (one equivalent with respect to Lewis acid) was added and the reaction was quenched with $p$ bromobenzaldehyde $\mathbf{2 a}$. The linear product $\mathbf{4 a a}$ was obtained as the sole product with high diastereoselectivity (entry 7). However difficulties were encountered in the purification procedures and a further optimization step was required. Addition of ${ }^{~} \mathrm{Bu} \mathrm{Al}_{2} \mathrm{AlCl}$ at the end of the reduction step and before addition of the aldehyde provided very good results in terms of yield, diastereoselectivity and purification (entries 8-9). It is worth noting that a catalytic amount ( 0.2 equiv) of aluminium salt was sufficient to retain its favourable impact.
Table 1. Optimization studies ${ }^{a}$

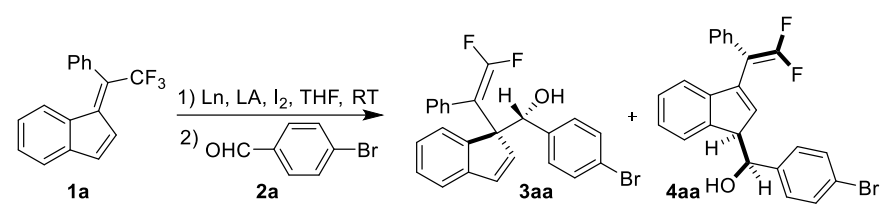

\begin{tabular}{lllcc}
\hline Entry & Ln & LA (equiv.) & $\begin{array}{c}\text { \% Yield } \\
\text { 3aa }\end{array}$ & $\begin{array}{c}\text { \% } \text { Yield }^{\mathbf{b}} \\
\mathbf{4 a a}(\% \mathbf{d e})^{\mathbf{c}}\end{array}$ \\
\hline 1 & $\mathrm{Dy}$ & $\mathrm{AlCl}_{3}(3)$ & 93 & n.o. \\
2 & $\mathrm{La}$ & $\mathrm{AlCl}_{3}(2)$ & 46 & $19(44)$ \\
3 & $\mathrm{La}$ & $\mathrm{AlCl}_{3}(1)$ & 20 & $25(78)$ \\
4 & $\mathrm{La}$ & $\mathrm{EtAlCl}_{2}(2)$ & 26 & $22(79)$ \\
5 & $\mathrm{La}$ & $\mathrm{Et}_{2} \mathrm{AlCl}(2)$ & 33 & $43(94)$ \\
6 & $\mathrm{La}$ & ${ }^{i} \mathrm{Bu}_{2} \mathrm{AlCl}(2)$ & 9 & $74(94)$ \\
$7^{\text {d }}$ & $\mathrm{La}$ & {$\left[\mathrm{LaI}_{3}\right](1)$} & n.o. & $77(90)$ \\
$8^{\text {d }}$ & $\mathrm{La}$ & {$\left[\mathrm{LaI}_{3}(1)\right] ;{ }^{i} \mathrm{Bu}_{2} \mathrm{AlCl}(2)$} & n.o. & $81(94)$ \\
$9^{\text {d }}$ & $\mathrm{La}$ & {$\left[\mathrm{LaI}_{3}(1)\right] ;{ }^{i} \mathrm{Bu} \mathrm{AlCl}_{2} \mathrm{Al}(0.2)$} & n.o. & $82(94)$ \\
\hline
\end{tabular}

a) Reaction conditions: Benzofulvene 1a $0.55 \mathrm{mmol}$, aldehyde 2a $0.5 \mathrm{mmol}$, Ln $0.5 \mathrm{mmol}$ and catalytic amount of iodine $(20 \mathrm{mg})$ in THF at room temperature. b) Isolated yields after silica gel column chromatography. c) de was determined from ${ }^{19} \mathrm{~F}$ NMR of crude reaction mixture. d) in situ preparation of $\mathrm{Lal}_{3}$ from $\mathrm{La}$ and $\mathrm{I}_{2}$.

With these optimized conditions in hand, we set out to investigate the scope of the reaction. A large range of aldehydes was compatible with these reaction conditions, including various substituted benzaldehydes, naphthyl and heteroaromatic aldehydes as well as linear and branched aliphatic aldehydes (Table 2). The use of benzaldehydes with strong electrondonating or withdrawing groups was compatible, although providing additional reaction outcomes that will be discussed below. The aryl group on the fulvene moiety could also be varied, showing good results with $p$-tolyl, $p$-chloro and $p$ dimethylaminophenyl or 2-thienyl groups (Table 2 ). It is interesting to note that $p$-dimethylaminophenylbenzofulvene $\mathbf{1 d}$ was completely unreactive when using the previously published $\mathrm{Dy} / \mathrm{AlCl}_{3}$ system, impeding any C-F activation in this case.

Table 2. Substrate scope ${ }^{a}$

\begin{tabular}{llll} 
En $\mathrm{RCHO}_{2}, \mathrm{RT}$ \\
\hline
\end{tabular}




\begin{tabular}{llll}
\hline 9 & $\mathrm{C}_{6} \mathrm{H}_{5}, \mathbf{1 a}$ & $-\mathrm{C}_{\left(-\mathrm{CH}_{3}\right)_{3}, \mathbf{2} \mathbf{j}}$ & $\mathbf{4 a j}, 76(100)$ \\
10 & $4-\mathrm{Me}-\mathrm{C}_{6} \mathrm{H}_{4}, \mathbf{1 b}$ & $4-\mathrm{Br}_{-}-\mathrm{C}_{6} \mathrm{H}_{4}, \mathbf{2 a}$ & $\mathbf{4 b a}, 74(96)$ \\
11 & $4-\mathrm{Cl}-\mathrm{C}_{6} \mathrm{H}_{4}, \mathbf{1 c}$ & $4-\mathrm{Br}_{-}-\mathrm{C}_{6} \mathrm{H}_{4}, \mathbf{2 a}$ & $\mathbf{4 c a}, 66(90)$ \\
12 & $4-\mathrm{N}(\mathrm{Me})_{2}-\mathrm{C}_{6} \mathrm{H}_{4}, \mathbf{1 d}$ & $4-\mathrm{Br}_{-} \mathrm{C}_{6} \mathrm{H}_{4}, \mathbf{2 a}$ & $\mathbf{4 d a}, 65(90)$ \\
13 & 2-Thienyl, 1e & $4-\mathrm{Br}_{-}-\mathrm{C}_{6} \mathrm{H}_{4}, \mathbf{2 a}$ & $\mathbf{4 e a}, 68(97)$ \\
\hline
\end{tabular}

a) Reaction conditions: Benzofulvene $\mathbf{1} 0.55 \mathrm{mmol}$, aldehyde $\mathbf{2} 0.5 \mathrm{mmol}$, La $1.0 \mathrm{mmol}$, iodine $0.5 \mathrm{mmol}$ and DIBAL-Cl $0.1 \mathrm{mmol}$ in THF at room temperature. b) Isolated yields after silica gel column chromatography. c) de was determined from ${ }^{19} \mathrm{~F}$ NMR of crude reaction mixture.

Single-crystals of the major diastereoisomer of the linear product 4ak could be obtained from the reaction with $p$-CNbenzaldehyde $\mathbf{2 k}$ and the structure was determined by X-Ray diffraction analysis (Table 3 and Figure 1). Most notably, it shows an angle of $61^{\circ}$ between the plane of the indenyl moiety and the plane containing the difluorovinyl part, revealing poor conjugation between both sub-structures, hence the absence of a conjugated planar diene structure. Further evidence, that the $\mathrm{CF}_{2}$-alkene is not conjugated with the indenyl part can be observed from the $\mathrm{C}=\mathrm{CF}_{2}$ bond length, which is identical to the previously reported structure on the unconjugated branched product $\mathbf{3}$ derived from benzaldehyde..$^{9}$ The phenyl group in 4ak is tilted out of the plane containing the difluorovinyl part by $34^{\circ}$. The bending of the cyano-substituted phenyl ring on the alcohol moiety towards the $\mathrm{CF}_{2}$ group leads to relatively short C-F and $\mathrm{C}-\mathrm{H}$ distances. However, this is probably due to packing effects, as no interaction between the $\mathrm{F}$ atoms and the protons on the aromatic ring could be determined in solution by ${ }^{1} \mathrm{H}-{ }^{19} \mathrm{~F}$ hetero nOe-experiments.

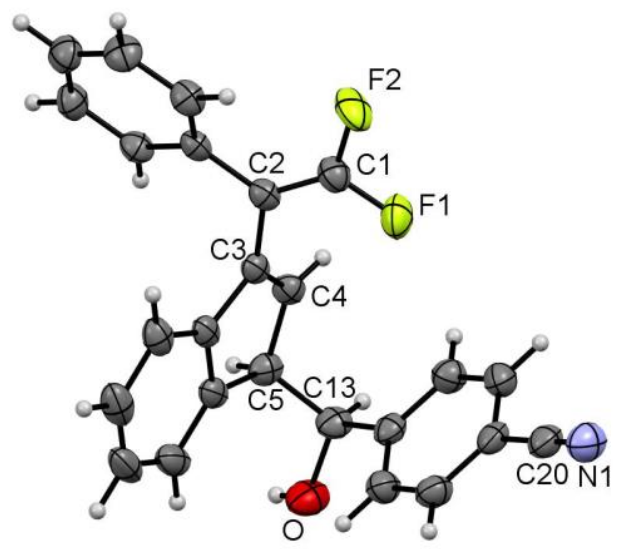

Figure 1. Single crystal X-ray structure of linear product 4ak.

A closer inspection of the crude ${ }^{19} \mathrm{~F}$ NMR spectra of the experiments involving strongly electron-withdrawing groups such as $p$ - $\mathrm{CF}_{3}, p$-nitro or $p$-CN on the aldehyde $(\mathbf{2} \mathbf{k}, \mathbf{I}, \mathbf{m})$, revealed the presence of a second product characterized by two additional doublets at around $-100 \mathrm{ppm}$, a typical feature of a diastereotopic aliphatic $\mathrm{CF}_{2}$ system. These unexpected products could be isolated by column chromatography in $15-30 \%$ yields depending on the electron-withdrawing character of the aromatic ring and were identified as the unprecedented ipso-substitution products 5 (Table 3 ). In addition, crystals suitable for XRD analysis were obtained for 5 am (Figure 2). A comparison of crystal structures of $\mathbf{5 a m}$ and starting fulvene $\mathbf{1 a}$ shows that the only difference is a slight elongation of the $\mathrm{C}\left(\right.$ exo) $-\mathrm{CF}_{3}$ to $\mathrm{C}($ exo)$\mathrm{CF}_{2} \mathrm{R}\left(\mathrm{R}=\mathrm{CH}(\mathrm{OH})\left(\mathrm{C}_{6} \mathrm{H}_{4}-p-\mathrm{NO}_{2}\right)\right)$ bond from 1.5043(16) to $1.515(3) \AA$ in agreement with the less electron-withdrawing character of the $\mathrm{CF}_{2} \mathrm{R}$ group.

Tuning the selectivity towards the ipso product has proved elusive so far by varying the temperature and/or employing additives, and further work is in progress.

Table 3. Scope of ipso substitution ${ }^{a}$

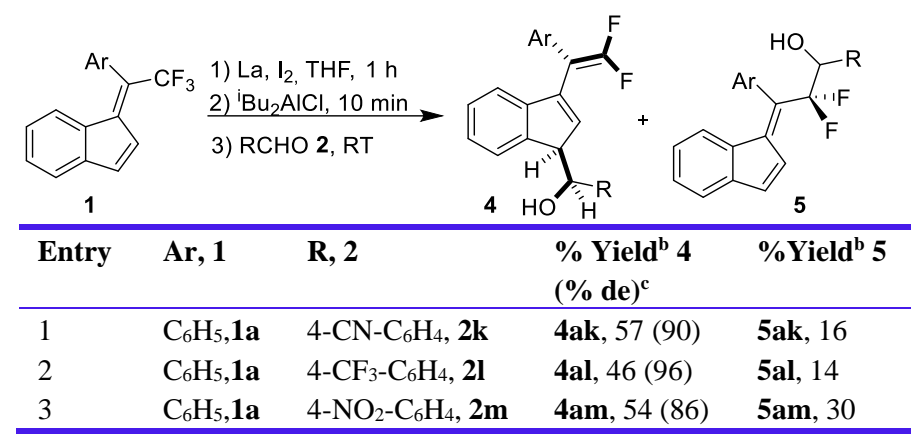

a) Reaction conditions: Benzofulvene $10.55 \mathrm{mmol}$, aldehyde $20.5 \mathrm{mmol}$, La $1.0 \mathrm{mmol}$, iodine $0.5 \mathrm{mmol}$ and DIBAL-Cl $0.1 \mathrm{mmol}$ in THF at room temperature. b) Isolated yields after silica gel column chromatography. c) de was determined from ${ }^{19} \mathrm{~F}$ NMR of crude reaction mixture.

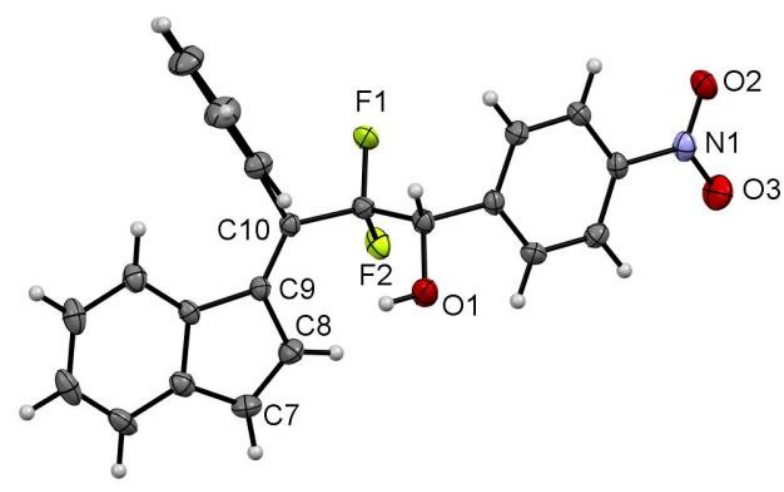

Figure 2. Single crystal X-ray structure of ipso product 5am.

We previously observed that with the $\mathrm{Dy} / \mathrm{AlCl}_{3}$ system the linear adduct of 1a with $p$-dimethylaminobenzaldehyde underwent spontaneous dehydration to yield the corresponding Z-alkene 6an in good yield and with high diastereoselectivity (Scheme 2). ${ }^{9}$ When we repeated this reaction with the new La/Lal 3 system we could observe the linear homoallylic alcohol product 4an in the crude ${ }^{19} \mathrm{~F}$ NMR spectrum. However, during purification on silica gel, dehydration of 4 an was observed, yielding the dark red benzofulvene 6an. A similar result was obtained with the 2thienyl-substituted benzofulvene 1e, which yielded 6en in good yield (Scheme 2). In contrast, the linear alcohols obtained with other aldehydes were stable under these conditions. In order to trigger the dehydration of compounds 4 in a more general fashion, different bases were tested. Only the reaction of 4 aa with LDA provided benzofulvene 6aa exclusively as the $Z$ isomer, 
however in low $25 \%$ yields, probably due to side reactions on the difluoroalkene moiety. Nevertheless, dehydration could be triggered by treatment with mesyl chloride and $\mathrm{NEt}_{3}$ to furnish efficiently a range of new difluorovinyl appended benzofulvenes 6, albeit with lower stereoselectivity (Table 4). Steric effects seem to drive the stereoselectivity of the formed alkenes, leading to lower de values for the more substituted aryl moieties in $6 \mathrm{ba}$ and $6 \mathrm{ca}$.

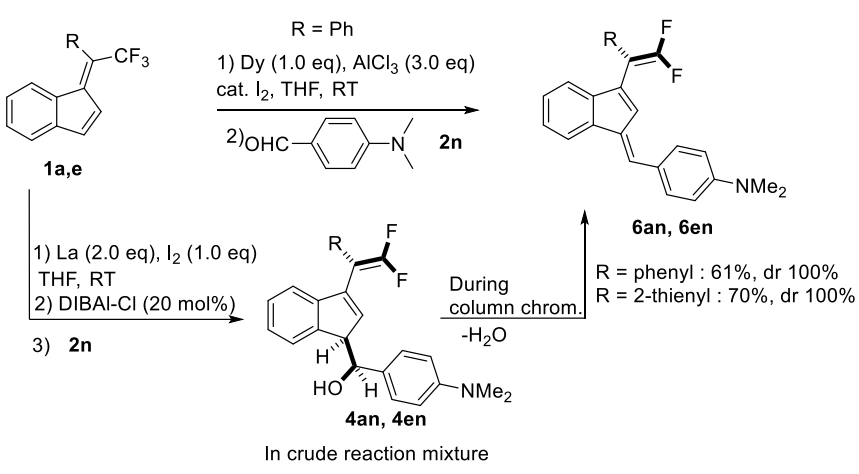

Scheme 2. Reaction with electron-donating aldehyde leading to dehydration of intermediate linear product.

Table 4. Scope of new benzofulvenes obtained by dehydration ${ }^{a}$
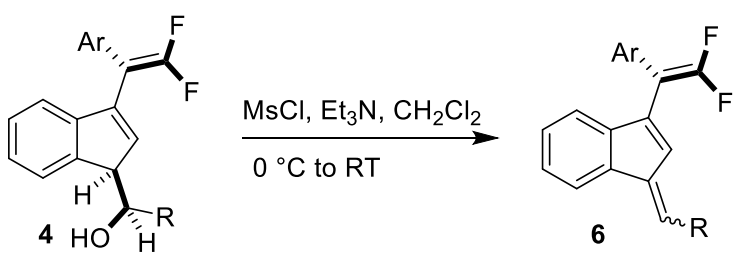

\begin{tabular}{lllll}
\hline Entry & $\mathbf{4}$ & $\mathbf{A r}$ & $\mathbf{R}$ & \%Yield $^{\mathbf{b}}(\mathbf{d e})^{\mathbf{c}} \mathbf{6}$ \\
\hline 1 & 4aa & $\mathrm{C}_{6} \mathrm{H}_{5}$ & 4- $\mathrm{Br}-\mathrm{C}_{6} \mathrm{H}_{4}$ & 6aa, 45 (70) \\
2 & 4ac & $\mathrm{C}_{6} \mathrm{H}_{5}$ & 4-Me- $\mathrm{C}_{6} \mathrm{H}_{4}$ & 6ac, 75 (76) \\
3 & 4ah & $\mathrm{C}_{6} \mathrm{H}_{5}$ & 2-Thiophene & 6ah, 68 (84) \\
4 & 4ba & 4-Me- $\mathrm{C}_{6} \mathrm{H}_{4}$ & 4- $\mathrm{Br}-\mathrm{C}_{6} \mathrm{H}_{4}$ & 6ba, 75 (52) \\
5 & 4ca & 4- $\mathrm{Cl}-\mathrm{C}_{6} \mathrm{H}_{4}$ & 4- $\mathrm{Br}-\mathrm{C}_{6} \mathrm{H}_{4}$ & 6ca, 85 (20) \\
\hline
\end{tabular}

a) Reaction conditions: Difluorovinylindene alcohol $40.2 \mathrm{mmol} \mathrm{Et}_{3} \mathrm{~N} 0.26$ mmol, methanesulfonyl chloride $0.22 \mathrm{mmol}$ in $\mathrm{CH}_{2} \mathrm{Cl}_{2} 4 \mathrm{~mL}$. b) Isolated yields after silica gel column chromatography. c) de was determined from ${ }^{19} \mathrm{~F}$ NMR of crude reaction mixture.

Benzofulvenes are interesting starting compounds in organometallic chemistry and have recently been investigated for material applications, such as chromophores for solar cells and OLEDs. ${ }^{12}$ These new compounds may therefore find useful applications. In addition, from a chemical point of view, these compounds have two reactive sites, the exocyclic fulvene double bond and the difluoroalkene moiety, ${ }^{13}$ so a large number of further transformations can be envisaged and are currently under investigation.

We then carried out some experiments towards the understanding of these highly regioselective processes. Preliminary mechanistic studies using ${ }^{19} \mathrm{~F}$ NMR on the $\mathrm{Dy} / \mathrm{AlCl}_{3}$ system had shown that transmetallation from Dy to Al was a plausible explanation for the selective formation of branched products. ${ }^{9}$ We have therefore studied the transmetallation from $\mathrm{La}$ to $\mathrm{Bu}_{2} \mathrm{AICl}$ and found that this process was much less efficient according to ${ }^{19} \mathrm{~F}$ NMR (see SI, Figure F2). Despite several attempts, an intermediate La-species could not be isolated and characterized by X-ray crystallography nor ESI-MS. We therefore turned our attention to DFT calculations to shine further light on the reaction mechanism. We initially calculated the structures of possible pentadienyllanthanum (pdl-La) intermediate complexes resulting from the $\mathrm{C}-\mathrm{F}$ activation process. For $\left[\mathrm{La}(\mathrm{pdl}) \mathrm{l}_{2}(\mathrm{THF})\right]$ and $\left[\mathrm{La}(\mathrm{pdl})_{2} \mathrm{l}(\mathrm{THF})\right]$ an $\eta^{5}$ coordination of the metal to the indenyl moiety was observed with no specific interaction between the metal and the $\mathrm{CF}_{2}$ group (see SI, section IV). The reactivity of these different pdl-La complexes with benzaldehyde was computed next. According to our modelisation, $\left[\mathrm{La}(\mathrm{pdl}) \mathrm{I}_{2}(\mathrm{THF})\right]$ would provide both the linear product (black profile in Scheme 3) and the ipso product (pink profile in Scheme 3) as their formations involve energetically competitive transition states $(12.6 \mathrm{kcal} / \mathrm{mol}$ vs. $17.6 \mathrm{kcal} / \mathrm{mol}$ which lies within the precision of the computational method), whereas the formation of the branched product was shown to be an unfavorable, reversible process (blue profile in Scheme 3). From these calculations, one would expect a mixture of the linear and ipso products. However, as a mixture is not observed experimentally, we studied the behavior of a possible $\left[\mathrm{La}(\mathrm{pdl})_{2} \mathrm{l}(\mathrm{THF})\right]$ species. In this case, although the two transition states are still competitive $(8.0 \mathrm{vs} .9 .5 \mathrm{kcal} / \mathrm{mol})$, the linear product is favored thermodynamically over the ipso product by more than $7 \mathrm{kcal} / \mathrm{mol}$ (Scheme 4). In addition, introducing an electron-withdrawing $p-\mathrm{NO}_{2}$-benzaldehyde lowers the energybarrier for the epsilon attack and therefore provides better access to the ipso product, in agreement with experiments (see SI, Schemes S2 and S3). As several bis(indenyl)lanthanide complexes have been crystallographically characterized, such species seem to be plausible reaction intermediates. ${ }^{14}$

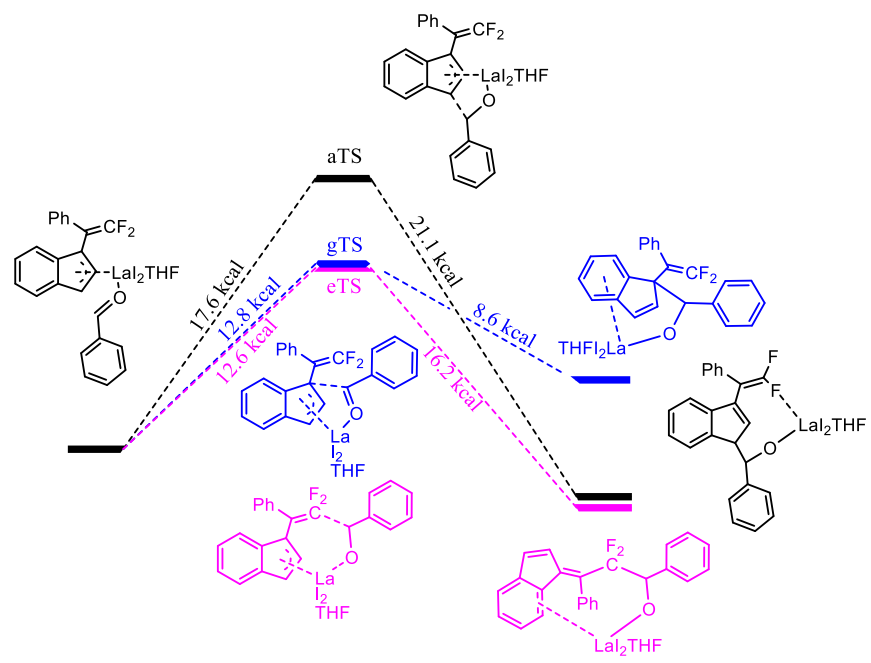

Scheme 3. DFT analysis of reaction of benzaldehyde with $\left[\mathrm{La}(\mathrm{pdl}) \mathrm{I}_{2}(\mathrm{THF})\right]$. 


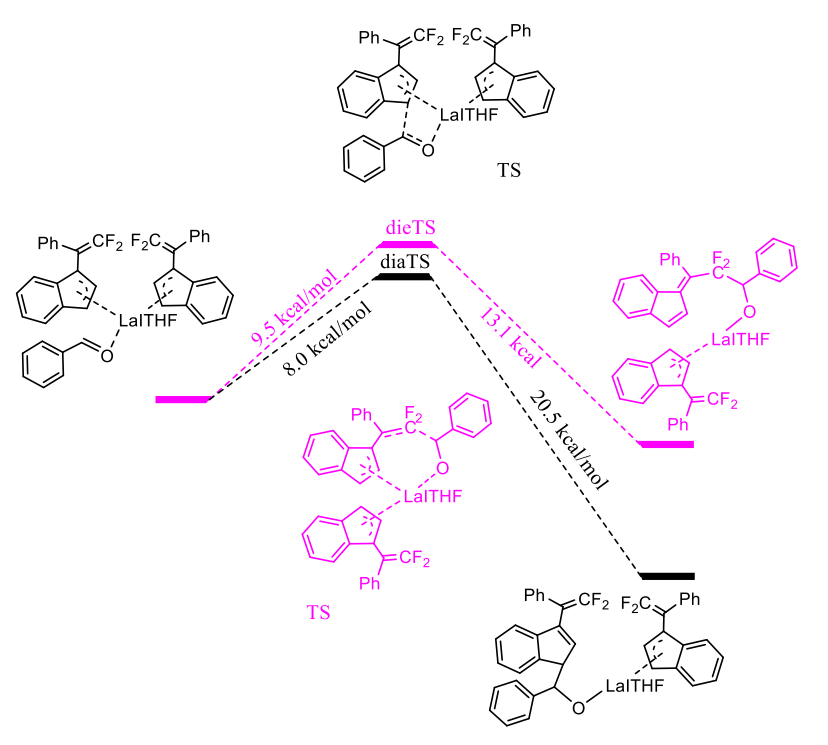

Scheme 4. DFT analysis of reaction of benzaldehyde with $\left[\mathrm{La}(\mathrm{pdl})_{2} \mathrm{l}(\mathrm{THF})\right]$.

In conclusion, we have shown that an appropriate combination of lanthanide metal and Lewis acid allows the regio and stereoselective transformation of trifluoromethylated dienes with a large range of aldehydes. Whereas the previously reported $\mathrm{Dy} / \mathrm{AlCl}_{3}$ combination afforded selective access to the branched product, the $\mathrm{La} / \mathrm{I}_{2} / \mathrm{DIBAL}-\mathrm{Cl}$ system has now given rise to highly selective linear products with excellent diastereoselectivity. The unexpected observation of ipso-substitution products in combination with initial mechanistic understanding from DFT analysis opens up new pathways towards further functionalization of the $\mathrm{CF}_{3}$ group. The newly obtained benzofulvenes carrying difluoroalkenes are currently under investigation for their applications in organic and organometallic synthesis as well as material sciences.

\section{Experimental Section}

In a glovebox under argon atmosphere, a mixture of freshly filed lanthanum metal (139 mg, $1.0 \mathrm{mmol}, 2.0$ equiv.), iodine (127 mg, 0.5 mmol, 1.0 equiv.) and benzofulvene 1 (0.55 mmol, 1.1 equiv.) was prepared in a Schlenk tube. THF $(1.5 \mathrm{~mL})$ was added slowly and the reaction was stirred for $1 \mathrm{~h}$ at room temperature. The reaction mixture turned to a dark brown/black solution, to which DIBAL-CI $(0.02 \mathrm{~mL}, 0.1$ mmol, 0.2 equiv.) was added and the resulting mixture was stirred for additional $10 \mathrm{~min}$. Aldehyde 2 ( $0.5 \mathrm{mmol}, 1.0$ equiv.) was added and stirring continued for another $1 \mathrm{~h}$. The reaction was quenched with aq. $\mathrm{HCl}(1 \mathrm{M}, 5 \mathrm{~mL})$ and extracted with diethyl ether $(15 \mathrm{~mL} \times 3)$ and the combined organic phase was dried over anhydrous $\mathrm{MgSO}_{4}$ and concentrated in vacuo. The crude product was purified by column chromatography (EA:PE/ 5:95 to 20:80).

\section{Acknowledgements}

We acknowledge financial support from the French ANR (project ANR-15-CE29-0020-01 ACTIV-CF-LAN), the CNRS and the
Université de Reims Champagne-Ardenne. L.M. is a senior member of the Institut Universitaire de France. Y.Y. acknowledges the Chinese Scholarship Council (CSC) for a PhD scholarship. CalMip is finally acknowledged for a generous grant of computing time. Financial support by CNRS, Conseil Regional Champagne Ardenne, Conseil General de la Marne, Ministry of Higher Education and Research (MESR) and EU-programme FEDER to the PIAneT CPER project is gratefully acknowledged.

Keywords: C-F activation $•$ lanthanides $•$ fulvene $\bullet$ C-C coupling - mechanism

[1] a) J. Han, A. M. Remete, L. S. Dobson, L. Kiss, K. Izawa, H. Moriwaki, V. A. Soloshonok, D. O'Hagan, J. Fluorine Chem. 2020, 239, 109639; b) J. Moschner, V. Stulberg, R. Fernandes, S. Huhmann, J. Leppkes, B. Koksch, Chem. Rev. 2019, 119, 10718-10801; c) T. Fujiwara, D. O'Hagan, J. Fluorine Chem. 2014, 167, 16-29; d) B. Ameduri, Chem Eur. J. 2018, 24, 18830-18841; e) Q. Fan, U. A. Méndez-Romero, X. Guo, E. Wang, M. Zhang, Y. Li, Chem. Asian. J. 2019, 14, 3085-3095;

[2] Selected reviews on fluorination methods: a) F.-G. Zhang, X.-Q. Wang, Y. Zhou, H.-S. Shi, Z. Feng, J.-A. Ma, I. Marek, Chem. Eur. J. 2020, 26 15378-15396; b) T. Fuchigami, S. Inagi, Acc. Chem. Res. 2020, 53, 322-334; c) R. Szpera, D. F. J. Moseley, L. B. Smith, A. J. Sterling, V. Gouverneur, Angew. Chem. Int. Ed. 2019, 58, 14824-14848; d) D. E. Yerien, S. Barata-Vallejo, A. Postigo, Chem. Eur. J. 2017, 23, 1467614701; e) M. G. Campbell, T. Ritter, Chem. Rev. 2015, 115, 612-633.

[3] a) H. Amii, K. Uneyama, Chem. Rev. 2009, 109, 2119-2183; b) T. Ahrens, T. Braun, Chem. Rev. 2015, 115, 931-972; c) A. Arora, J. D. Weaver, Acc. Chem. Res. 2016, 49, 2273-2283; d) Y. Wang, A. Liu, Chem. Soc. Rev. 2020, 49, 4906-4925.

[4] a) F. Jaroschik, Chem. Eur. J. 2018, 24, 14572-14582; b) J.-D. Hamel, J.-F. Paquin, Chem. Commun. 2018, 54, 10224-10239; c) T. Fujita, K. Fuchibe, J. Ichikawa, Angew. Chem. Int. Ed. 2019, 58, 390-402; d) F. Tian, G. Yan, J. Yu, Chem. Commun. 2019, 55, 13486-13505; e) R. Gupta, A. K. Jaiswal, D. Mandal, R. D. Young, Synlett 2020, 31, 933937.

[5] a) X.-T. Gao, Z. Zhang, X. Wang, J.-S. Tian, S.-L. Xie, F. Zhou, J. Zhou, Chem. Sci. 2020, 11, 10414-10420; b) D. Ding, Y. Lan, Z. Lin, C. Wang, Org. Lett. 2019, 21, 2723-2730; c) Y. Jin, J. Wu, Z. Lin, Y. Lan, C. Wang, Org. Lett. 2020, 22, 5347-5352; d) Y. He, D. Anand, Z. Sun, L. Zhou, Org. Lett. 2019, 21, 3769-3773; e) G. Chen, L. Wang, X. Liu, P. Liu, Adv. Synth. Catal. 2020, 362, 2990-2996; f) Yisen Liu, Chunmei Li, Chuan Liu, Jingjing He, Xianghu Zhao, Song Cao, Tetrahedron Lett. 2020, 61, 151940; g) S. B. Lang, R. J. Wiles, C. B. Kelly, G. A. Molander, Angew. Chem. Int. Ed. 2017, 56, 15073-15077; Angew. Chem. 2017, 129, 15269-15273; h) T. Ichitsuka, T. Fujita, J. Ichikawa, ACS Catal. 2015, 5, 5947-5950 ; i) Y. Huang, T. Hayashi, J. Am. Chem. Soc. 2016, 138, 12340-12343; j) K. Fuchibe, H. Hatta, K. Oh, R. Oki, J. Ichikawa, Angew. Chem. Int. Ed. 2017, 56, 5890-5893; k) T. Xiao, L. Li, L. Zhou, J. Org. Chem. 2016, 81, 7908-7916; I) X. Lu, X.-X. Wang, T.-J. Gong, J.-J. Pi, S.-J. He, Y. Fu, Chem. Sci. 2019,10, 809-814; m) Y. Cai, H. Zeng, C. Zhu, C. Liu, G. Liu, H. Jiang, Org. Chem. Front. 2020, 7, 1260-1265; n) R. J. Wiles, J. P. Phelan, G. A. Molander, Chem. Commun. 2019, 55, 7599-7602.

[6] Direct ipso-substitution: a) N. A. Phillips, G. J. Coates, A. J. P. White, M. R. Crimmin, Chem. Eur. J. 2020, 26, 5365-5368; b) H. Zeng, C. Zhu, H. Jiang, Org. Lett. 2019, 21, 1130-1133; c) S.-S. Yan, D.-S. Wu, J.-H. Ye, L. Gong, X; Zeng, C.-K. Ran, Y.-Y. Gui, J. Li, D.-G. Yu, ACS Catal. 2019, 9, 6987-6992. Formal ipso-substitution via isolated boronintermediate: d) R. Kojima, S. Akiyama, H. Ito, Angew. Chem. Int. Ed. 2018, 57, 7196-7199; e) P. H. S. Paioti, J. Del Pozo, M. S. Mikus, J. Lee, M. J. Koh, F. Romiti, S. Torker, A. H. Hoveyda, J. Am. Chem. Soc. 2019, 141, 19917-19934; f) P. Gao, G. Wang, L. Xi, M. Wang, S. Li, Z. Shi, Chin. J. Chem. 2019, 37, 1009-1014; g) P. Gao, C. Yuan, Y. Zhao, 
Z. Shi, Chem. 2018, 4, 2201-2211; h) Y. Liu, Y. Zhou, Y. Zhao, J. Qu, Org. Lett. 2017, 19, 946-949.

[7] N. Takabumi, H. Masayoshi, Y. Masahiko, Y. Yoshioka, Y. Noriko, A. Akira, K. Mayumi, M. Takuichi, K. Itsumaro, Chem. Pharm. Bull. 1989 37, 177-183.

[8] H. Chen, D. Anand, L. Zhou, Asian J. Org. Chem. 2019, 8, 661-664.

[9] T. Kumar, F. Massicot, D. Harakat, S. Chevreux, A. Martinez, K. Bordolinska, P. Preethanuj, R. Kokkuvayil Vasu, J.-B. Behr, J.-L. Vasse, F. Jaroschik, Chem. Eur. J. 2017, 23, 16460-16465.

[10] T. Kumar, A. Ben Hassine, A. Martinez, D. Harakat, S. Chevreux, F. Massicot, M. Taillefer, J.-B., Behr, J.-L. Vasse, F. Jaroschik, J. Vis. Exp. 2018, 137, e57948.

[11] a) Y. Yamamoto, N. Asao, Chem. Rev. 1993, 93, 2207-2293; b) S. Wu, Y. Li, S. Zhang, J. Org. Chem. 2016, 81, 8070-8076; c) X. Y. Cao, F. Huang, S. Zhang, Synlett 2019, 30, 1437-1441.
[12] a) M. Fischer, K. Fitschen, M. Schmidtmann, R. Beckhaus Organometallics 2019, 38, 3760-3767; b) S. Tortorella, M. Mastropasqua Talamo, A. Cardone, M. Pastore, F. De Angelis, J. Phys.: Condens. Matter 2016, 28, 074005; c) A. Cappelli, V. Razzano G. Fabio, M. Paolino, G. Grisci, G. Giuliani, A. Donati, R. Mendichi, W. Mróz, F. Villafiorita-Monteleone, C. Botta, RSC Adv. 2015, 5, 101377101385.

[13] a) G. Chelucci, Chem. Rev. 2012, 112, 1344-1462; b) X. Zhang, S. Cao, Tetrahedron Lett. 2017, 58, 375-392.

[14] a) J. Cheng, D. Cui, W. Chen, T. Tang, B. Huang, Polyhedron 2004, 23, 1075-1080; b) Y. Wang, Y. Lei, S. Chi, Y. Luo, Dalton Trans. 2013, 42, 1862-1871; c) C.-T. Qian, G. Zou, W.-L. Nie, J. Sun, D. A. Lemenovskii, M. V. Borzov, Polyhedron 2000, 19, 1955-1959. 
